\title{
A. Asadi, S.M. Mousavi Kouhpar, J. Neyestani, A. Hojabri-Nobari. Sasanian and Early Islamic settlement patterns north of the Persian Gulf
}

\section{Sébastien Gondet}

\section{(2) OpenEdition}

\section{Journals}

Édition électronique

URL : http://journals.openedition.org/abstractairanica/41517

DOI : 10.4000/abstractairanica.41517

ISSN : 1961-960X

Éditeur :

CNRS (UMR 7528 Mondes iraniens et indiens), Éditions de l'IFRI

Référence électronique

Sébastien Gondet, « A. Asadi, S.M. Mousavi Kouhpar, J. Neyestani, A. Hojabri-Nobari. Sasanian and Early Islamic settlement patterns north of the Persian Gulf », Abstracta Iranica [En ligne], Volume 34-35-36 | 2017, document 10, mis en ligne le 15 juillet 2016, consulté le 03 octobre 2020. URL : http:// journals.openedition.org/abstractairanica/41517 ; DOI : https://doi.org/10.4000/abstractairanica. 41517

Ce document a été généré automatiquement le 3 octobre 2020.

Tous droits réservés 


\title{
A. Asadi, S.M. Mousavi Kouhpar, J. Neyestani, A. Hojabri-Nobari. Sasanian and Early Islamic settlement patterns north of the Persian Gulf
}

\author{
Sébastien Gondet
}

\section{RÉFÉRENCE}

A. Asadi, S.M. Mousavi Kouhpar, J. Neyestani, A. Hojabri-Nobari. « Sasanian and Early Islamic settlement patterns north of the Persian Gulf ». Vicino Oriente, 17, 2013, p. 21-38.

Les années 2000 concernant le sud de l'Iran central et menées dans des plaines côtières de Būšehr et Sīrāf ainsi que dans les vallées intermontagneuses voisines de Lāmard ou Bastak. Depuis les années 2000, on note dans cette région de l'Iran une recrudescence des études régionales et des fouilles qui, mis à part les fouilles anglaises de Sīrāf dans les années 70, a longtemps été délaissée par les archéologues.

2 Les AA. se concentrent sur le Sassanide et surtout sur la transition avec la période islamique. Excepté pour la région de Sīrāf, qui devient un port important après l'avènement de l'Islam, les données de prospection indiquent une diminution importante du nombre de sites après la chute de l'empire sassanide. Selon les AA., cette diminution serait liée à la disparation (hypothétique) des structures étatiques qui permettaient de maintenir des réseaux de communications et surtout d'irrigation nécessaires dans des milieux peu favorables à l'agriculture. Si certaines données demanderaient à être considérées avec plus de précision et un regard plus critique, on pense ici aux réseaux d'irrigation qui semblent être tous considérés a priori comme sassanides, cet article pose les bases de problématiques qui devront être explorées plus précisément dans le futur: modes d'adaptation à des milieux très divers; solutions 
d'irrigation ; réseaux de communication dans une topographie très escarpée ; facteurs de développement ou de déprise de l'occupation.

\section{AUTEURS}

\section{SÉBASTIEN GONDET}

CNRS, Paris 